\title{
Sensitivity of subglacial Lake Vostok's flow regime on environmental parameters
}

\author{
Malte Thoma ${ }^{\mathrm{a}, \mathrm{b}}$ Christoph Mayer ${ }^{\mathrm{b}}$ Klaus Grosfeld ${ }^{\mathrm{a}}$ \\ ${ }^{a}$ Alfred Wegener Institute for Polar and Marine Research, \\ Bussestrasse 24, 27570 Bremerhaven, Germany \\ ${ }^{\mathrm{b}}$ Bayerische Akademie der Wissenschaften, Kommission für Glaziologie, \\ Alfons-Goppel Str. 1180539 München, Germany
}

\begin{abstract}
Subglacial lakes provide unique habitats, but the exact nature of physical and geochemical conditions are still a matter of debate and await direct sampling of water. Due to its isolation from external atmospheric forcing other environmental parameters influence the flow characteristics within the lake. In this study we use an improved treatment of the physical processes at the ice-water boundary interface to identify and quantify the impact of (1) the geothermal heat flux, (2) the heat flux from the lake into the ice, (3) the influence of the salinity of the lake water, and (4) the ice thickness on the size of the freezing area and the freeze/melt rates. We show that the modelled basal mass imbalance (that is the produced melt water minus the re-frozen water) depends on the geothermal heating as well as the heat flux into the ice. The circulation and the temperature distribution within subglacial Lake Vostok are rather stable against variations of geothermal heat flux, heat flux into the ice sheet, salinity of the lake, and small changes of the ice thickness above the lake. However, the flow regime for any subglacial lake with less than $2000 \mathrm{~m}$ ice thickness above, will be substantially different from those that experience higher pressures. This is because the buoyancy-temperature relationship reverses at this depth.
\end{abstract}

Key words: Numerical ocean modelling, ice-ocean interaction, subglacial environment, Lake Vostok, sensitivity study, Antarctica

$P A C S$ : 


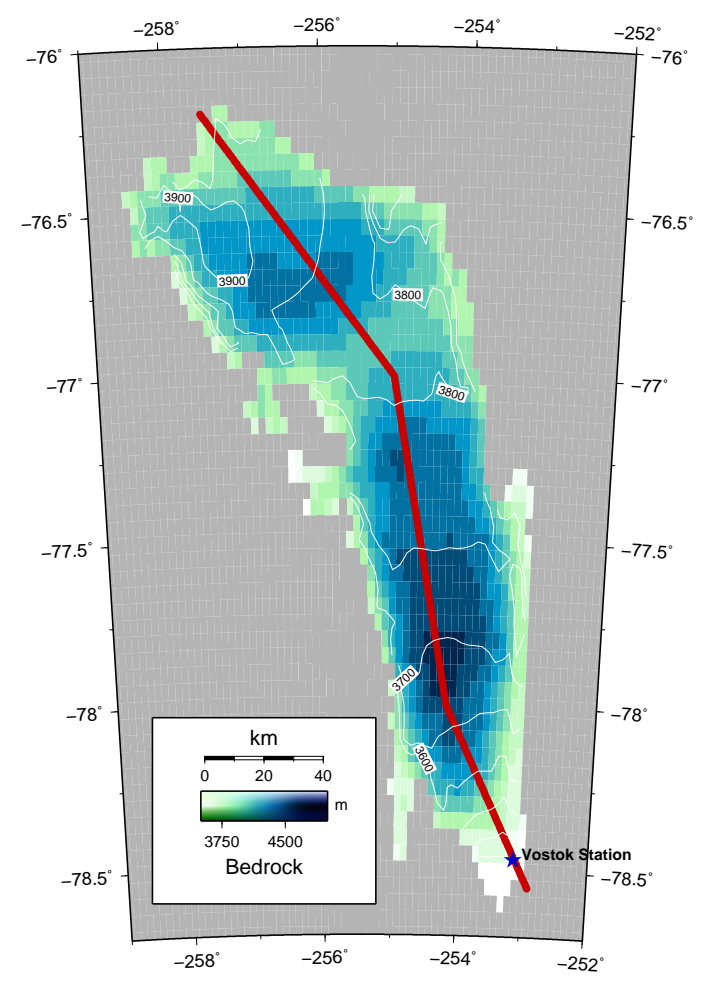

Fig. 1. Bathymetry of Lake Vostok where contours show the ice draft (Studinger et al., 2004). The red line indicates a profile transect and the blue star indicates the position of the Russian Vostok research station.

\section{Introduction}

In a recent paper Thoma et al. (2007) presented a three-dimensional numerical model to investigate the circulation within subglacial Lake Vostok, Antarctica. As direct observations underneath about $4000 \mathrm{~m}$ of ice are nearly impossible or at least very expensive (e.g., Gavaghan, 2002; Priscu et al., 2003; Inman, 2005), physical parameters (e.g., water column depth, salinity, heat conduction into the ice) can only be guessed or estimated by indirect measurements and hence include considerable uncertainties. The standard model configuration presented in Thoma et al. (2007) uses the bathymetry model published by Studinger et al. (2004) (Fig. 1) and treats Lake Vostok as a closed system according to mass conservation. The configuration is based on the most appropriate parameters currently available, but no systematical estimation of the impact of varying physical environmental parameters and boundary conditions has been made so far. The only other study that addresses uncertainties is by Mayer et al. (2003) who investigated the impact of the water's salinity on circulation and basal ice formation in Lake Vostok. Currently, a new bathymetric model is developed by Filina et al. (2008). This will allow additional sensitivity studies on the impact of ice draft and water column thickness on

Email address: Malte. Thoma@awi.de (Malte Thoma). 
Lake Vostok's flow regime in the future. The aim of this study is to close this gap by analysing the sensitivity of the model output (which are the circulation pattern, the basal mass loss, the temperature distribution, and the freezing area within Lake Vostok) to specific forcing parameters. In fact, the circulation pattern as described in Thoma et al. (2007) is stable against most parameter variations. Hence, we use the turbulent kinetic energy as a scalar and easier to compare representative. After a brief description of the numerical model in Section 2, we present results for different sensitivity studies in Section 3, namely the geothermal heat flux (Section 3.2), the heat flux into the ice shelf (Section 3.3), the lake water's salinity (Section 3.4), and different ice thicknesses above the lake (Section 3.5). In the final Section 4, we discuss the relevance of our results for Lake Vostok and other subglacial lakes and their implication for future numerical studies as well as for explorations of Lake Vostok and other subglacial Antarctic lakes.

\section{Theoretical model and setup}

We use the three-dimensional fluid dynamics model Rombax (Thoma et al., 2006a) especially designed for sub-ice shelf or subglacial environments. Only a few improvements to the model code, as described in Thoma et al. (2007), have been made; namely, the treatment of the physical processes at the icelake boundary interface, a slightly different vertical $\sigma$-layer discretization, and the use of a spatial filter to smooth the bedrock topography and the ice draft (Thoma et al., 2006b).

The first modification, concerning the physical process at the ice-water interface is based on the conservation of energy (heat) and salinity and on an empirical equation for the pressure dependent freezing point (Grosfeld et al., 1997; Gerdes et al., 1999; Holland and Jenkins, 1999). In the subglacial environment the heat conduction into the ice is important. We re-implemented its treatment to ensure energy conservation.

The latter two modifications increase the numerical stability of the model output by decreasing the unavoidable pressure gradient error in $\sigma$-coordinate models (Mellor et al., 1993; Ezer and Mellor, 1997; Ly and Jiang, 1999). Filtering of about $14 \%$ (4\%) of the bedrock (ice draft) nodes, where the gradient exceeds a specified limit of $4 \%$ (equivalent to $2.3^{\circ}$ ), ensures an upper limit of the topographic slope of about $9 \%$ (4\%). Thus, both values drop below the upper limit of 10\%, proposed by Mellor and Blumberg (1985), implying that the implemented diffusion scheme acting along and perpendicular to $\sigma$-coordinates is sufficient. 


\section{Results}

\subsection{Revised standard model configuration}

The model improvements with respect to Thoma et al. (2007) have only a negligible impact on the circulation pattern within Lake Vostok, but the temperature and flow velocities do change. By far the largest impact has the revised energy balance formulation at the ice-lake interface. This reduces the water temperature within the lake for about 10\% (Table 1). Because the melting and freezing rates are highly sensitive to temperature differences, any change in the boundary temperature field leads to a significant impact on the mass balance at the ice sheet's base. Hence, the values of the melting rate, the freezing area and the average freezing rate are affected stronger than the temperature. As temperature gradients are reduced, the turbulent kinetic energy and flow velocities are reduced, too. The horizontal flow (in the order of $1 \mathrm{~mm} / \mathrm{s}$ ) is largest at the bottom and the top of the lake while the vertical velocity (in the order of $10 \mu \mathrm{m} / \mathrm{s}$ ) is largest in the water column's centre. In Table 1 the diagnostic parameters of the revised standard model configuration introduced here are compiled and compared with those of Thoma et al. (2007). The black circles, indicating the revised standard model configuration in Figs. 2-4 and 6, have slightly different values compared to Thoma et al. (2007).

Only few and deduced data is available by now to validate our model results. However, the revised values for the freezing rate (see Thoma et al., 2007, for a detailed discussion), the basal ice loss (Petit, 2003), and the northward extending freezing area (e.g., Siegert et al., 2000) correlate well with these

\begin{tabular}{lr|crr} 
& Unit & $\begin{array}{c}\text { Thoma } \\
\text { et al. }(2007)\end{array}$ & This work & Change \\
\hline Freezing area & $\left(\mathrm{km}^{2}\right)$ & 3500 & 4350 & $+24 \%$ \\
Average freeze rate & $(\mathrm{cm} / \mathrm{a})$ & 3.0 & 1.7 & $-43 \%$ \\
Mean temp. (North) & $\left({ }^{\circ} \mathrm{C}\right)$ & -3.07 & -2.76 & $-10 \%$ \\
(South) & $\left({ }^{\circ} \mathrm{C}\right)$ & -3.00 & -2.71 & $-10 \%$ \\
Basal mass loss & $(\mathrm{mm} / \mathrm{a})$ & 5.6 & 3.1 & $-45 \%$ \\
Fresh water flux & $\left(\mathrm{m}^{3} / \mathrm{s}\right)$ & 2.78 & 1.55 & $-44 \%$ \\
Basal ice loss & $\left(10^{-2} \mathrm{~km}^{3} / \mathrm{a}\right)$ & 9.80 & 5.77 & $-41 \%$ \\
Turbulent kinetic energy & $\left(10^{-2} \mathrm{~cm}^{2} / \mathrm{s}^{2}\right)$ & 2.88 & 2.05 & $-30 \%$ \\
Table 1 & & & &
\end{tabular}

Table 1

Compilation of updated diagnostic parameters, compared to the previous work of Thoma et al. (2007). 
indirect observations.

\subsection{Geothermal heat flux}

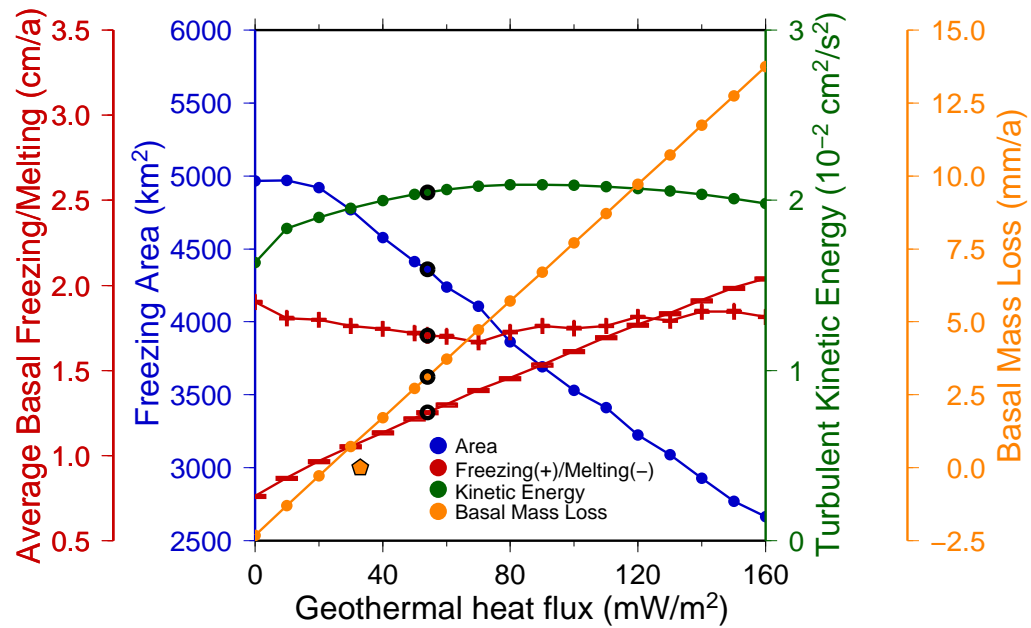

Fig. 2. Dependence of the freezing area (blue), the average basal melt $(-) /$ freeze rate $(+)$ (red), the basal mass loss (orange), and the turbulent kinetic energy (green) on different geothermal heat fluxes. Additional black circles indicate results of the standard model configuration. The orange pentagon indicates the position, where geothermal heat would be balanced by the heat loss through the ice if this would be constant (see text).

Using a simple numerical model of the ice sheet thermal regime, Siegert (2000) postulated the geothermal heat flux at the base of the Antarctic ice sheet to be between $37 \mathrm{~mW} / \mathrm{m}^{2}$ and $64 \mathrm{~mW} / \mathrm{m}^{2}$ to ensure basal melting; and according to Maule et al. (2005), who interpreted satellite magnetic data, the geothermal heat flux underneath the Antarctic Ice Sheet varies from less than $50 \mathrm{~mW} / \mathrm{m}^{2}$ to more than $150 \mathrm{~mW} / \mathrm{m}^{2}$. The value for the Lake Vostok area, used in the standard model configuration, is $54 \mathrm{~mW} / \mathrm{m}^{2}$ (Maule et al., 2005), which is also a common average value for the whole of Antarctica. According to an energy balance model by Petit (2003), the geothermal heat flux over the lake is only about $46 \mathrm{~mW} / \mathrm{m}^{2}$. Fig. 2 shows the results for geothermal heat fluxes, varying from zero to $160 \mathrm{~mW} / \mathrm{m}^{2}$. The impacts on the flow regime (not shown), the turbulent kinetic energy, and the freeze rate are negligible, but the freezing area, the average melt rate, and the basal mass loss do depend significantly on the amount of geothermal heat. The basal mass loss is defined as the difference between molten ice and frozen water at the ice's base. Note, that the dependence of the basal mass loss in this experiment is linear. With no geothermal heat flux at all, the net basal mass loss is positive $(\approx 2.3 \mathrm{~mm} / \mathrm{a})$, leading to a net basal ice gain. As the lake's average depth is calculated to be $350 \mathrm{~m}$, it would take about 150000 years to freeze the whole lake. If the heat flux into the ice would be constant everywhere (see Section 3.3), the basal mass 
exchange would be balanced at the position indicated by the orange pentagon in Fig. 2. But in our model the heat flux into the ice is assumed to be zero in areas where freezing takes place, a smaller amount about $23 \mathrm{~mW} / \mathrm{m}^{2}$ is sufficient to maintain the lake's volume.

\subsection{Heat conduction into the ice}

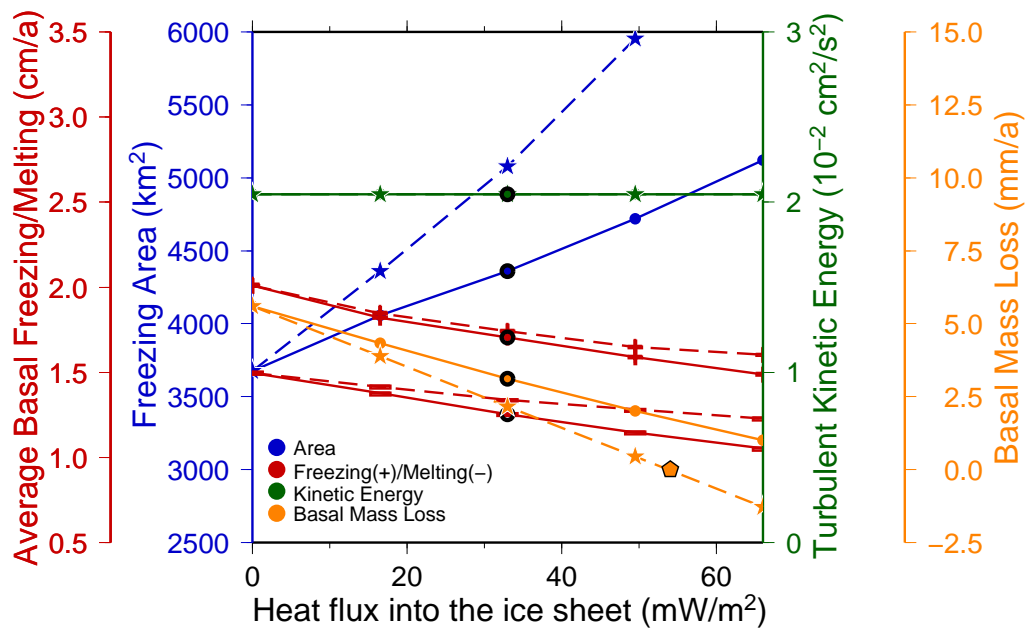

Fig. 3. As Fig. 2, but for different heat fluxes into the ice. The dashed lines and the stars (partly covered) indicate a scenario, where heat conduction also applies to freezing zones (see text).

The heat flux $Q_{\text {Ice }}=\lambda \Delta T / H=33 \mathrm{~mW} / \mathrm{m}^{2}$ from the lake into the ice sheet, used for the standard model configuration, is estimated from the difference between the average annual mean surface temperature and the average basal freezing point temperature $\Delta T=-59 \mathrm{~K}$, the heat conductivity $\lambda=2.1 \mathrm{~W} /(\mathrm{K} \mathrm{m})$, and the ice thickness at Vostok Station $H=3740 \mathrm{~m}$ (Mayer et al., 2003). The dashed lines and the stars in Fig. 3 show the results, if the heat flux is applied to the entire ice sheet base. Increasing heat extraction through the ice sheet reduces the effective boundary layer potential to melt ice. Hence, the average melt (freeze) rate decreases slightly about $45 \mu \mathrm{m} / \mathrm{a}$ per $\mathrm{mW} / \mathrm{m}^{2}\left(60 \mu \mathrm{m} /\right.$ a per $\left.\mathrm{mW} / \mathrm{m}^{2}\right)$, while the freezing area increases significantly by about $45 \mathrm{~km}^{2}$ per $\mathrm{mW} / \mathrm{m}^{2}$. At the same time, the basal mass loss is reduced by about $0.1 \mathrm{~mm} /$ a per $\mathrm{mW} / \mathrm{m}^{2}$. When the geothermal heat is equal to the heat flux into the ice, the basal mass loss reaches zero, indicated by the pentagon in Fig. 3. However, in areas where freezing takes place (as is the case in the southern part of Lake Vostok), the temperature in the ice just above the lake is more likely to be constant (e.g., Grosfeld and Thyssen, 1994). Hence, the temperature gradient and therefore the heat flux into the ice is likely to be zero in these areas. Model results for this more realistic scenario are indicated by the solid lines in Fig. 3. The average melt (freeze) rate is reduced more strongly, about $75 \mu \mathrm{m} / \mathrm{a}$ per $\mathrm{mW} / \mathrm{m}^{2}\left(79 \mu \mathrm{m} /\right.$ a per $\left.\mathrm{mW} / \mathrm{m}^{2}\right)$ than in 


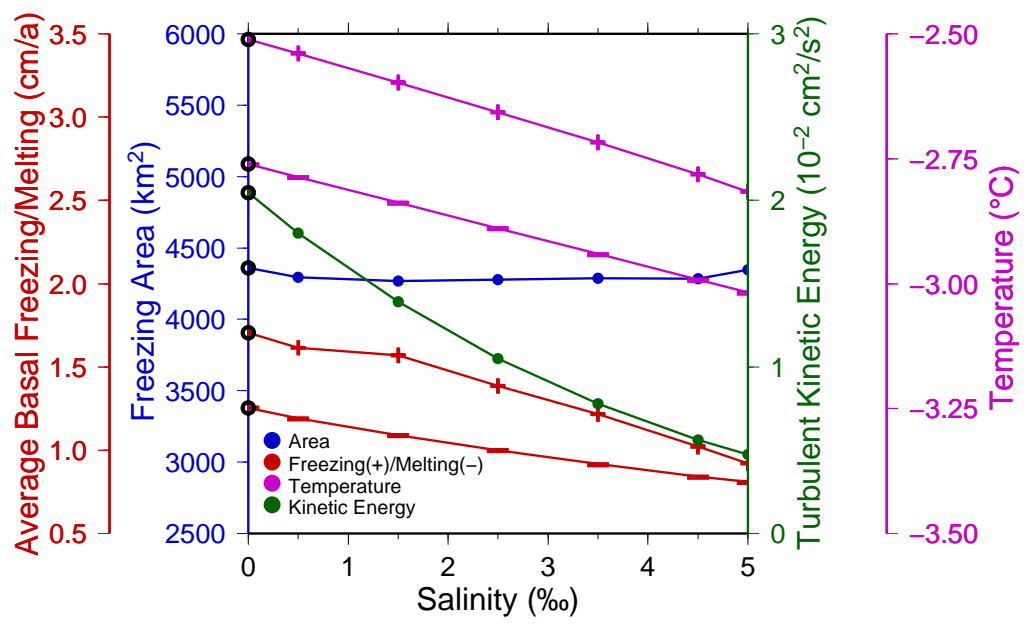

Fig. 4. As Fig. 2, but for different salinities. Here, the impact of salinity on the maxima $(+)$ and minima(-) ice-lake interface temperatures (magenta) replaces the constant basal mass loss.

the former scenario and the freezing area increase is about halved $\left(22 \mathrm{~km}^{2}\right.$ per $\mathrm{mW} / \mathrm{m}^{2}$ ). While the heat flux approaches zero, both curves merge as a matter of course. The turbulent kinetic energy is rather constant in this experiment.

Our study encloses a range of the heat flux into the ice from zero to $66 \mathrm{~mW} / \mathrm{m}^{2}$, this is reasonable. The surface temperature in Antarctica is closely correlated with the height above sea level. According to Fortuin and Oerlemans (1990) the temperature lapse rate is $-14.3 \mathrm{~K} / \mathrm{km}$. For a hypothetical subglacial lake, closer to Antarctica's edge, the ice thickness may be $H=1000 \mathrm{~m}$ and the corresponding temperature difference would be $\Delta T=-20 \mathrm{~K}$. From this a heat flux of $Q_{\text {Ice }}=42 \mathrm{~mW} / \mathrm{m}^{2}$ would follow, which is still well below our maximum value.

\subsection{Salinity}

Until water samples are taken from Lake Vostok it remains unclear if the water is slightly saline or pure. Siegert (2000) combined radio-echo sounding data and satellite radar altimetric data to conclude that the salinity is likely to be between $0.00 \%$ and $0.05 \%$. Analyses of accreted ice from the Vostok ice core generally indicate a low salinity, although variable in detail $(0.4-1.2 \%$ Souchez et al. (2000); 0.1-1.0\% Souchez et al. (2003)). Nevertheless, some authors argue that the lake water could be quite pure (Priscu et al., 1999; Gorman and Siegert, 1999; Siegert et al., 2001). The only model study so far including a slight salinity of 1.2\% (Mayer et al., 2003), observed an increased (nearly doubled) transport, a reduced freezing area, and a slight temperature decrease of about $0.05 \mathrm{~K}$ per $\%$ compared to the pure-water study. In this study we increase the lake water's salinity up to $5 \%$, so that the estimated 
salinity of the lake will be covered by our analysis. In general, the stratification in a saline subglacial lake is more stable than in a pure fresh water case. This is due to the effect that melt water is colder and hence denser than ambient fresh water which leads to sinking of surface waters in most parts of the lake and fosters mixing of the water column. In a saline regime, the density contrast between melted (cool, dense) and ambient (warmer, saline, less dense) water masses is reduced, hence, salinity reduces mixing. From these considerations follow that bottom water masses, warmed by geothermal heat, can easier rise in a fresh water than in a saline environment, which reduces melting.

Our model results (Fig. 4) do support an interface water temperature decrease (of about $0.056 \mathrm{~K}$ per \%o). However, with our more sophisticated model (that includes a better implementation of the pressure and salinity dependent freezing point calculation), the transport (and therefore the turbulent kinetic energy) decreases significantly (about $0.35 \cdot 10^{-2} \mathrm{~cm}^{2} / \mathrm{s}^{2}$ per \%o). Because salinity decreases the pressure-dependent freezing point (Foldvik and Kvinge, 1974; Fofonoff and Millard, 1983), the temperatures in Lake Vostok drop. As salinity stabilises the water column it counteracts the driving forces geothermal heat flux and melting, and our model results seem to be more likely than those of Mayer et al. (2003) with respect to the decreased turbulent kinetic energy. Furthermore, the decreased flow velocities result in a less efficient transport of warmer bottom water to the ice cover as in a pure fresh water regime, resulting in a decrease of the average melt and freeze rates. The freezing area and the basal mass loss (not shown) are relatively independent of salinity.

\subsection{Ice load}

The main driving forces for the circulation within Lake Vostok are the ice draft-dependent melting/freezing and the geothermal heat flux. Therefore, temperature gradients are of uttermost importance to understand the stability of a water column within Lake Vostok. If a small water volume changes its potential temperature (with respect to the surrounding water mass) its density changes, too. According to the adjacent water mass, it will either rise or sink. The equation of state, which formulates the density of water subject to temperature, salinity, and pressure $\rho=\rho(T, S, p)$ is highly nonlinear (Jackett and McDougall, 1995). Hence, warming may either lead to rising or sinking, depending on the salinity and pressure (or equivalently depth). The coloured isopycnals in Fig. 5 show the density of fresh water for different depths and temperatures for a corresponding salinity of zero. The points of maximum density (points of inflection) are connected by a dashed line. Whether warming leads to buoyancy increase or decrease depends on the water mass properties relative to this dashed line. In the depth where Lake Vostok is positioned (indicated as the original shaded area), warming increases the buoyancy. Hence, 


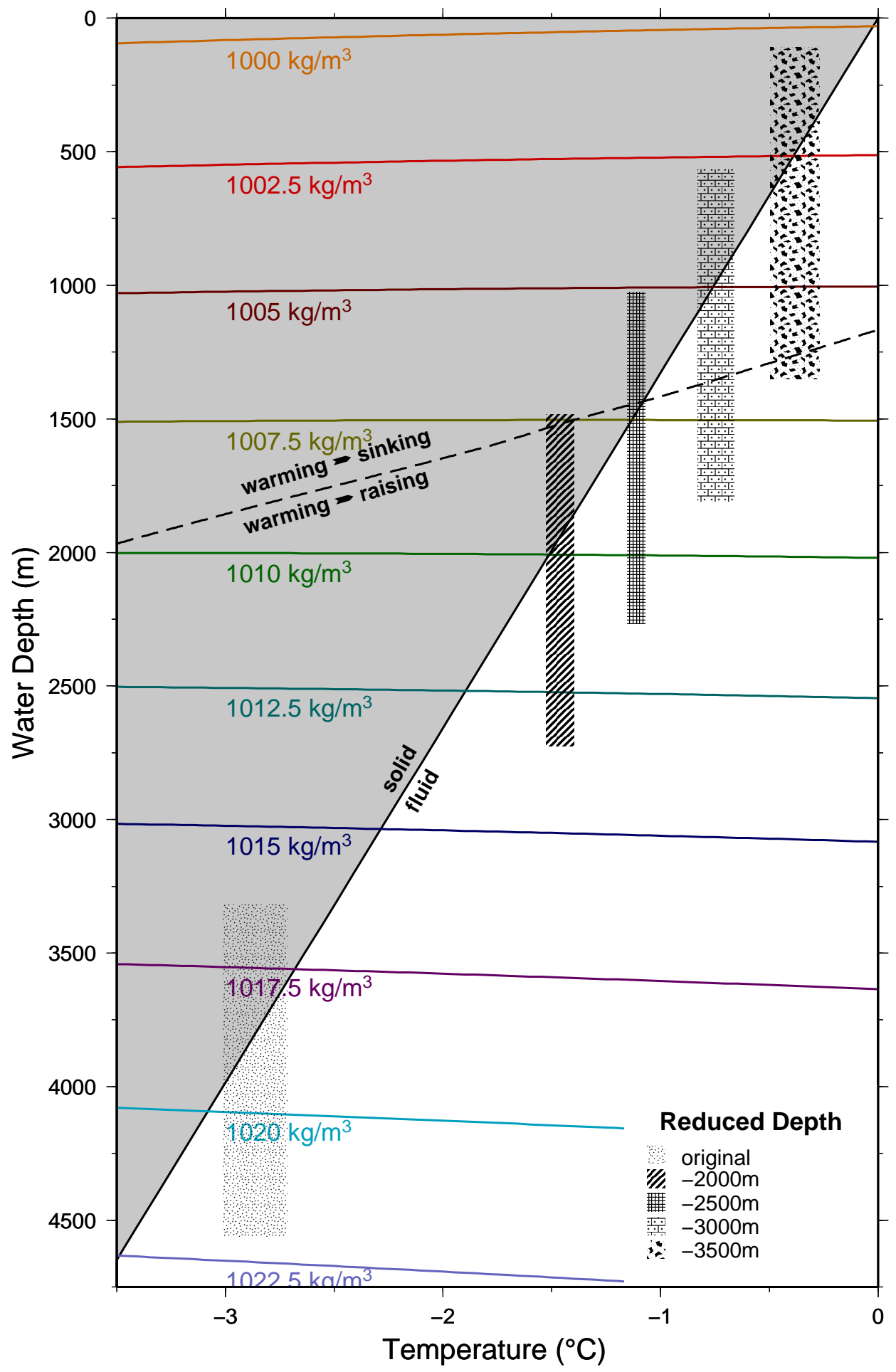

Fig. 5. Water depth and temperature dependence of isopycnals (Jackett and McDougall, 1995). The solid line shows the depth-dependent freezing point of fresh water (Fofonoff and Millard, 1983), the dashed line connects the isopycnal's inflection points and indicates the line of maximum density. Patterned areas show the captured space of temperatures and equivalent water depth for Lake Vostok with different (artificially reduced) ice load thicknesses. The grey shaded area above the solidus line represents supercooled water masses with freezing capability. Note, that the vast majority of nodes within Lake Vostok is well below the solidus line. 


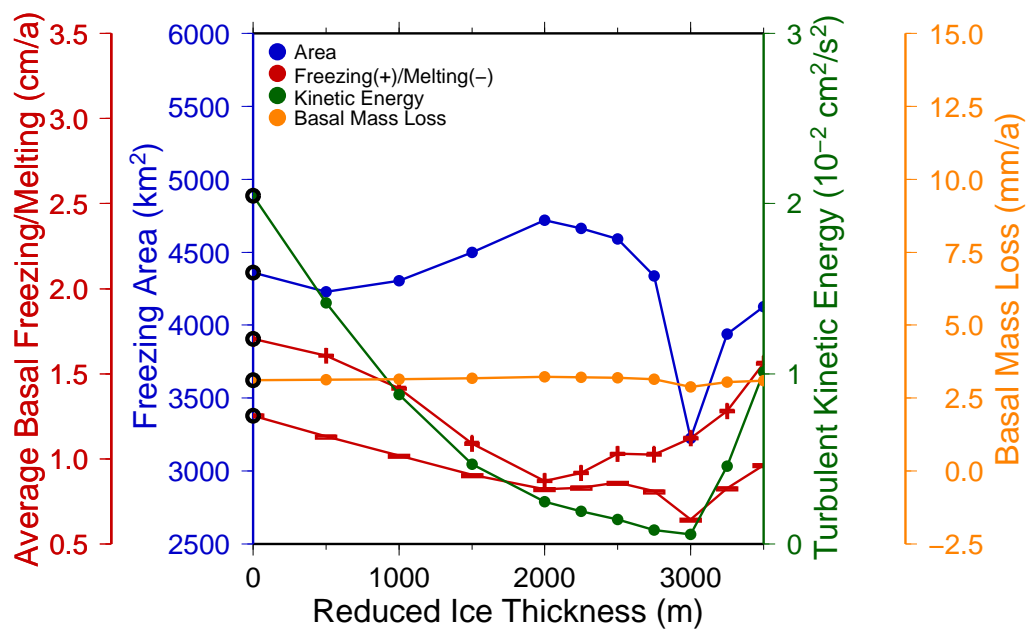

Fig. 6. As Fig. 2, but for different ice load thicknesses. Values for the x-axis represent the reduction in ice thickness based on the inital ice thickness of about $4000 \mathrm{~m}$.

warmer water rises to the lake's surface. If the pressure is reduced and a subglacial lake occupies shallower depths, closer to or even beyond the dashed line, the circulation regime will change. This regime change distinguishes oceanic case from lake case circulations (Wüest and Carmack, 2000). In this study we artificially reduce the depth (ice load) of Lake Vostok to study different regimes. As the lake itself covers about $1200 \mathrm{~m}$ depth (from its shallowest part to its greatest depth), a transition zone between about 2000 to $3500 \mathrm{~m}$ reduction of the original ice thickness does exist, where the lake is partly above and partly below the dashed line in Fig. 5 .

Fig. 6 shows that the basal mass loss is independent of the ice thickness above the lake, but that the freezing area, the average melt and freeze rates, and the turbulent kinetic energy do change. The closely correlated average melt/freeze rates and the turbulent kinetic energy decline significantly while the transition zone from the oceanic case to the lake case is approached, but the freezing area varies only little (around $3900 \pm 150 \mathrm{~km}^{2}$ ). During the transition (at about $3000 \mathrm{~m}$ ice reduction), the turbulent kinetic energy collapses completely, and the freezing area is decreased significantly. However, when the lake case stratification establishes, the freeze/melt rates, the freezing area, and the flow increase again. Compared to the ocean case described in Thoma et al. (2007), the flow establishes with a reversed circulation pattern (not shown).

The south-north temperature cross sections in Fig. 7 for lakes in different depths reveal the effect of the ocean case-lake case transition on the temperature distribution within the lake. (For the exact position of the cross section see Fig. 1.) The different shaded areas in Fig. 5 indicate temperature and depth ranges the artificial lake settings bestrode. According to the pressure dependent freezing point, the water gets warmer while the ice draft (and equivalently the depth of the lake) is reduced. If the ice load is decreased by $2000 \mathrm{~m}$ (Fig. 7a), the temperature structure within the lake is, despite the 

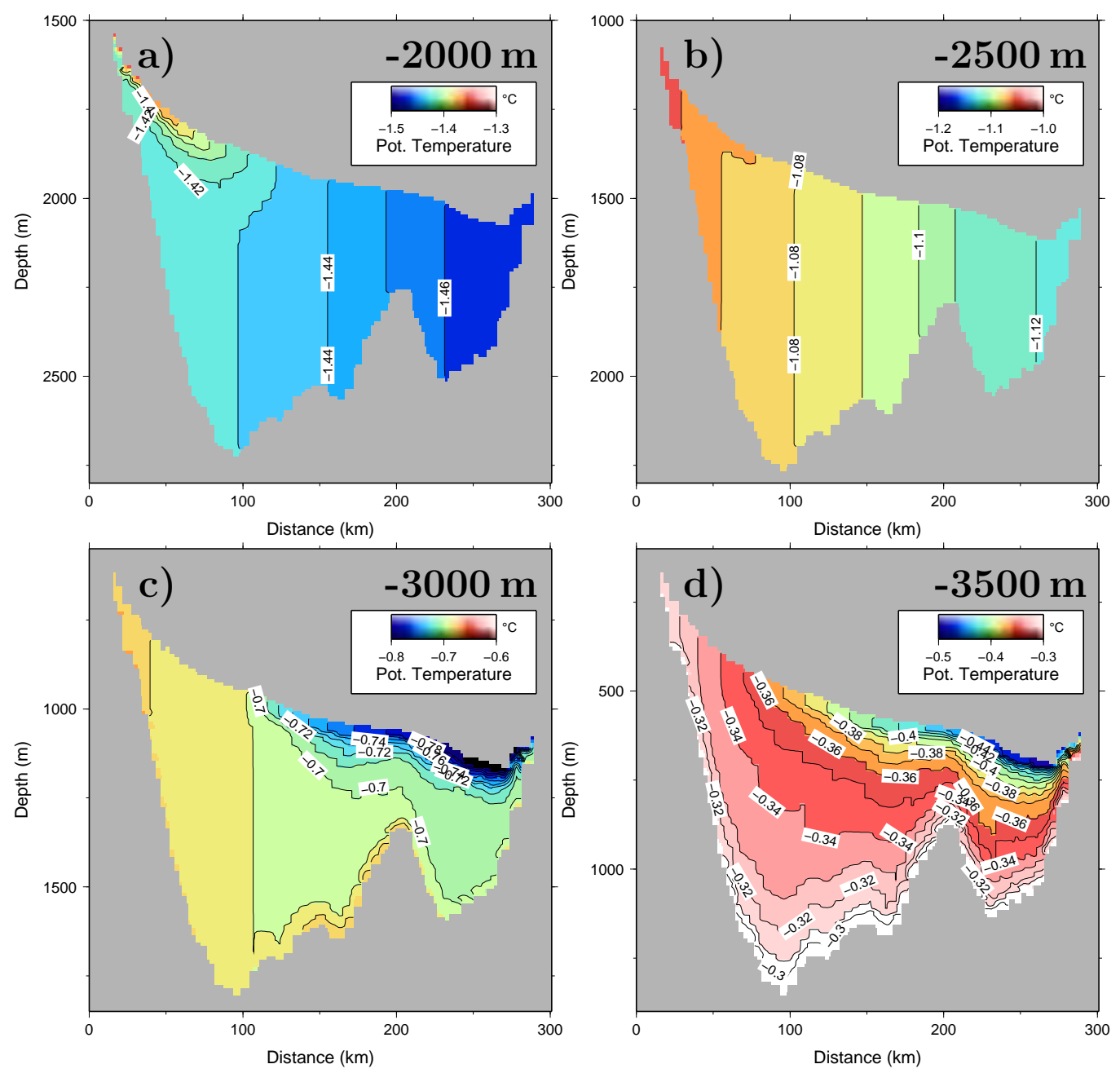

Fig. 7. South-north temperature cross section across Lake Vostok, assuming Lake Vostok at different depths. The amount of ice load reduction is indicated.

higher temperatures, still quite similar to the original Lake Vostok case (compare Thoma et al., 2007, Fig. 5): The warmest waters are close to the surface and a vertically stratified water column exists only where freezing takes place. However, in shallower lakes the warmest waters are most dense. Hence, they are confined to the bottom. As soon as the upper (and warmest) layers of the lake reach the critical depth (indicated by the dashed line in Fig. 5), convection starts until stability is restored. If the ice thickness is reduced by about $2500 \mathrm{~m}$ (Fig. 7b), the freezing-induced vertical stratification in the southern tip of the lake is dissolved. Further pressure reduction (Fig. 7c) reverses the temperature profile and melting-induced cooling in the lake's northern part stabilises the water column. Finally, if the ice load is so much reduced that the lake's condition relate to the lake case (meaning the whole lake is positioned above the dashed line in Fig. 5) the complete water column is vertically stratified (Fig. 7d). 


\section{Discussion and conclusions}

We investigated the impact of different physical and environmental parameters on the circulation and temperature distribution within Lake Vostok. Our conclusion is that the circulation pattern as well as the temperature-dependent stability as described in Thoma et al. (2007) was found to be stable with respect to variability in most parameters, namely, geothermal heat flux, heat flux into the ice sheet, and salinity. The only exception is the transition that takes place if the pressure within the lake exerted by the ice sheet load is reduced so that the lake regime switches from the oceanic case to the lake case. While the details of the circulation pattern within a specific lake surely depend on the bathymetry and ice draft, the ice thickness above a lake defines the stratification of the lake's water column. Most subglacial lakes, including the maybe first-to-be-probed Lake Ellsworth (Siegert et al., 2006), are covered by $3000 \pm 460 \mathrm{~m}$ of ice (Siegert, 2000; Siegert et al., 2005) and will have a temperature profile similar to Lake Vostok's: a homogeneous water column where melting takes place and a stratified water column in the shallower part where freezing occurs. But some lakes, where the ice thickness is about or even below the critical value indicated by the dashed line in Fig. 5, do exist (Siegert, 2000, 2005) and will have a lake case stratification with the warmest water at the bottom. From our analysis it became clear that at least $2000 \mathrm{~m}$ of ice would have to be removed to change the regime within Lake Vostok. But during the last glacial cycles, the ice thickness never ever came close to this limit; according to Huybrechts (2002) (supported also by Ritz et al., 2001), the surface elevation at Vostok Station has been varying only from $+50 \mathrm{~m}$ (during interglacials) to $-150 \mathrm{~m}$ (during periods of full glaciation) for the last four glacial cycles. Hence, the only regime shift Lake Vostok might have experienced could have been during changes in the ice surface slope (Siegert, 2005), extension changes (Erlingsson, 2006), or during its formation phase if the lake has already existed during this period (Duxbury et al., 2001; Siegert, 2004; Pattyn, 2004).

Salinity does not have such a huge impact on the flow regime as some studies propose (Souchez et al., 2000, 2003; Siegert et al., 2003; Mayer et al., 2003), we do only observe a reduction in transport as salinity stabilises the water column. The freezing area is independent of salinity variations. However, its implication on possible life within subglacial lakes may be crucial (Siegert et al., 2001, 2003; Souchez et al., 2003; Christner et al., 2006).

Geothermal heat flux at the lake's bottom as well as heat flux into the ice determine the freezing area and basal mass loss. As the heat flux into the ice will vary over the area, it can be assumed, that even a smaller geothermal heat flux (above $23 \mathrm{~mW} / \mathrm{m}^{2}$ ) than expected (about $54 \mathrm{~mW} / \mathrm{m}^{2}$ ) will maintain a constant lake's growth. 
The existence of a planar surface ice slope is much more essential to maintain a subglacial lake and to prevent produced melt water from leaving a topographic hollow by flowing uphill (Siegert, 2005). This result can easily be extended to other subglacial lakes. As geothermal heating does exist everywhere, all subglacial lakes will most probably have a drainage system and it is most likely that plenty of them are connected to each other (Clarke, 2006; Wingham et al., 2006; Bell et al., 2007; Fricker et al., 2007). Hence, future model studies should include mechanisms to permit mass flow into and out of the lake.

Beside the important role in storage and leakage of huge water masses within the subglacial hydrological network of Antarctica (Fricker et al., 2007), we propose a coupling of our model to a thermodynamic ice model (e.g., Pattyn et al., 2004) which will lead to implications upon the current stability of the Lake Vostok-ice sheet system.

Acknowledgement: This work was funded by the DFG through grant MA33471-2. The authors wish to thank Andrea Bleyer for proof reading as well as Irina Filina, Claude P. Jaupart, and two anonymous reviewers for helpful suggestions which improved the manuscript.

\section{References}

Bell, R. E., Studinger, M., Shuman, C. A., Fahnestock, M. A., Joughin, I., 2007. Large subglacial lakes in East Antarctica at the onset of fast-flowing ice streams. Nature 445, doi: 10.1038/nature05554.

Christner, B. C., Royston-Bishop, G., Foreman, C. F., Arnold, B. R., Tranter, M., Welch, K. A., Lyons, W. B., Tsapin, A. I., Studinger, M., Priscu, J. C., 2006. Limnological conditions in Subglacial Lake Vostok, Antarctica. Limnol. Oceanogr. 51 (6), doi: 10.1038/nature05554.

Clarke, G. K. C., Apr 2006. Glaciology: Ice-sheet plumbing in Antarctica. Nature 440, 1000-1001, doi: 10.1038/4401000a.

Duxbury, N. S., Zotikov, I. A., Nealson, K. H., Romanovsky, V. E., Carsey, F. D., 2001. A numerical model for an alternative origin of Lake Vostok and its exobiological implications for Mars. J. Geophys. Res. 106 (E1), 14531462.

Erlingsson, U., 2006. Lake Vostok behaves like a 'captured lake' and may be near to creating an Antarctic jökulhlaup. Geogr. Ann. 88A, 1-7.

Ezer, T., Mellor, G. L., 1997. Simulations of the atlantic ocean with a free surface sigma coordinate ocean model. J. Geophys. Res. 102 (C7), 1564715657.

Filina, I. Y., Blankenship, D. D., Thoma, M., Lukin, V. V., Valery, N. M., Sen, M. K., 2008. New 3D bathymetry and sediments distribution in Lake 
Vostok: Implication for pre-glacial origin and numerical modeling of the internal processes within the lake. Earth Pla. Sci. Let.Submitted.

Fofonoff, N. P., Millard, R. C., 1983. Algorithms for computation of fundamental properties of seawater. UNESCO Technical papers in marine science $44,29$.

Foldvik, A., Kvinge, T., 1974. Conditional instability of sea water at the freezing point. Deep-Sea Res. 21, 169-197.

Fortuin, J. P. F., Oerlemans, J., 1990. Parameterization of the annual surface temperature and mass balance of Antarctica. Ann. Glaciol. 14, 78-84.

Fricker, H. A., Scambos, T., Bindschadler, R., Padman, L., 2007. An active subglacial water system in west Antarctica mapped from space. Science 315 (5818), 1544-1548, doi: 10.1126/science.1136897.

URL http://www . sciencemag. org/cgi/content/abstract/315/5818/1544

Gavaghan, H., 2002. Life in the deep freeze. Nature 415, 828-830, doi: 10.1038/415828a.

Gerdes, R., Determann, J., Grosfeld, K., 1999. Ocean circulation beneath filchner-ronne ice shelf from three-dimensional model results. J. Geophys. Res. C7, 15827-15841.

Gorman, M. R., Siegert, M. J., 1999. Penetration of Antarctic subglacial lakes by VHF electromagnetic pulses: Information on the depth and electrical conductivity of basal water bodies. J. Geophys. Res. 104 (B12), 2931129320.

Grosfeld, K., Gerdes, R., Determann, J., 1997. Thermohaline circulation and interaction beneath ice shelf cavities and the adjacent open ocean. J. Geophys. Res. 102 (C7), 15595-15610.

Grosfeld, K., Thyssen, F., 1994. Temperature investigation and modeling on Filchner- Ronne Ice Shelf, Antarctica. Annals of Glaciology 20, 377-385.

Holland, D. M., Jenkins, A., 1999. Modeling thermodynamic ice-ocean interaction at the base of an ice shelf. J. Phys. Oceanogr. 29, 1787-1800.

Huybrechts, P. a., 2002. Sea-level changes at the LGM fromice-dynamic reconstructions of the Greenland and Antarctic ice sheets during the glacial cycles. Quaternary Sci. Rev. 21, 203-231.

Inman, M., 2005. Antarctic drilling: The plan to unlock Lake Vostok. Science 310 (5748), 611-612, doi: 10.1126/science.310.5748.611.

Jackett, D. R., McDougall, T. J., 1995. Minimal adjustment of hydrographic profiles to achieve static stability. J. Atmos. Ocean. Technol. 12, 381-389.

Ly, L. N., Jiang, L., 1999. Horizontal pressure gradient errors of the monterey bay sigma coordinate ocean model with various grids. Journal of Oceanography $55,87-97$.

Maule, C. F., Purucker, M. E., Olsen, N., Mosegaard, K., Jul. 2005. Heat Flux Anomalies in Antarctica Revealed by Satellite Magnetic Data. Science 309, 464-467, doi: 10.1126/science.1106888.

Mayer, C., Grosfeld, K., Siegert, M., 2003. Salinity impact on water flow and lake ice in Lake Vostok, Antarctica. Geophys. Res. Lett. 30 (14), 1767, doi:10.1029/2003GL017380. 
Mellor, G. L., Blumberg, A. F., 1985. Modeling vertical and horizontal diffusivities with the sigma coordinate system. Mon. Wea. Rev. 113, 1379-1383.

Mellor, G. L., Ezer, T., Oey, L.-Y., 1993. The pressure gradient conundrum of sigma coordinate ocean models. J. Atmos. Ocean. Technol. 11, 1126-1134.

Pattyn, F., 2004. Comment on the comment by M. J. Siegert on "A numerical model for an alternative origin of Lake Vostok and its exobiological implications for Mars" by N. S. Duxbury et al. J. Geophys. Res. 109 (E11004), doi:10.1029/2004JE002329.

Pattyn, F., de Smedt, B., Souchez, R., 2004. Influence of subglacial Vostok lake on the regional ice dynamics of the Antarctic ice sheet: a model study. J. Glaciol. 50 (171), 583-589.

Petit, J. R., Apr. 2003. Ice water exchanges in Lake Vostok constrained by an energy balance model. EGS - AGU - EUG Joint Assembly, Abstracts from the meeting held in Nice, France, 6-11 April 2003, Abstract \#3628.

Priscu, J. C., Adams, E. E., Lyons, W. B., Voytek, M. A., Mogk, D. W., Brown, R. L., McKay, C. P., Takacs, C. D., Welch, K. A., Wolf, C. F., Kirshtein, J. D., Avci, R., 1999. Geomicrobiology of Subglacial Ice Above Lake Vostok, Antarctica. Science 286 (5447), 2141-2144, doi:10.1126/science.286.5447.2141.

URL http://www . sciencemag. org/cgi/content/abstract/286/5447/2141

Priscu, J. C., Bell, R. E., Bulat, S. A., Ellis-Evans, C., Kennicutt II, M. C., Lukin, V. V., Petit, J.-R., Powell, R. D., Siegert, M. J., Tabacco, I., 2003. An international plan for Antarctic subglacial lake exploration. Polar Geography 27, 69-83.

Ritz, C., Rommelaere, V., Dumas, C., 2001. Modeling the evolution of Antarctic ice sheet over the last 420,000 years: Implications for altitude changes in the Vostok region. J. Geophys. Res. 106 (D23), 31943-31964.

Siegert, M. J., 2000. Antarctic subglacial lakes. Earth Sci. Rev. 50, 29-50.

Siegert, M. J., 2004. Comment on "A numerical model for an alternative origin of Lake Vostok and its exobiological implications for Mars" by N. S. Duxbury, I. A. Zotikov, K. H. Nealson, V. E. Romanovsky, and F. D. Carsey. J. Geophys. Res. 109 (E02007), 1-3, doi:10.1029/2003JE002176.

Siegert, M. J., 2005. Lakes beneath the ice sheet: The occurrence, analysis and future exploration of Lake Vostok and other Antarctic subglacial lakes. Annu Rev Earth Pl Sc 33, 215-245, doi: 10.1146/annurev.earth.33.092203.122725.

Siegert, M. J., Behar, A., Bentley, M., Blake, D., Bowden, S., Christoffersen, P., Cockell, C., Corr, H., Cullen, D. C., Edwards, H., Ellery, A., Ellis-Evans, C., Griffiths, G., Hindmarsh, R., Hodgson, D. A., King, E., Lamb, H., Lane, L., Makinson, K., Mowlem, M., Parnell, J., Pearce, D. A., Priscu, J., Rivera, A., Sephton, M. A., Sims, M. R., Smith, A. M., Tranter, M., Wadham, J. L., Wilson, G., Woodward, J., 2006. Exploration of Ellsworth Subglacial Lake: a concept paper on the development, organisation and execution of an experiment to explore, measure and sample the environment of a West Antarctic subglacial lake. Rev. Env. Sci. Bio.doi: 10.1007/s11157-006-91099 . 
Siegert, M. J., Carter, S., Tabacco, I. E., Popov, S., Blankenship, D. D., 2005. A revised inventory of Antarctic subglacial lakes. Anatarct Sci 17 (3), 453460, doi:10.1017/S0954102005002889.

Siegert, M. J., Ellis-Evans, J. C., Tranter, M., Mayer, C., Petit, J.-R., Salamatin, A., Priscu, J. C., 2001. Physical, chemical and biological processes in Lake Vostok and other Antarctic subglacial lakes. Nature 414, 603-609.

Siegert, M. J., Kwok, R., Mayer, C., Hubbard, B., 2000. Water exchange between the subglacial Lake Vostok and the overlying ice sheet. Nature 403, 643-646, doi: 10.1038/35001049.

Siegert, M. J., Tranter, M., Ellis-Evans, J. C., , Priscu, John C. Lyons, W. B., 2003. The hydrochemistry of Lake Vostok and the potential for life in Antarctic subglacial lakes. Hydr. Proc. 17, 795-814.

Souchez, R., Petit, J. R., Jouzel, J., DeAngelis, M., Tison, J., 2003. Reassessing lake Vostok's behavior from existing and new ice core data. Earth Pla. Sci. Let. 217, 163-170.

Souchez, R., Petit, J. R., Tison, J. L., Jouzel, J., Verbeke, V., 2000. Ice formation in subglacial Lake Vostok, Central Antarctica. Earth Pla. Sci. Let. 181 (4), 529-538.

Studinger, M., Bell, R. E., Tikku, A. A., 2004. Estimating the depth and shape of subglacial Lake Vostok's water cavity from aerogravity data. Geophys. Res. Lett. 31 (L12401), doi:10.1029/2004GL019801.

Thoma, M., Grosfeld, K., Lange, M. A., 2006a. Impact of the Eastern Weddell Ice Shelves on water masses in the eastern Weddell Sea. J. Geophys. Res. 111 (C12010), doi:10.1029/2005JC003212.

Thoma, M., Grosfeld, K., Lange, M. A., 2006b. The impact of mixing parameterisation and bathymetry filtering on the simulated hydrography along steep continental shelf regions in terrain following ocean models. FRISP Report 17.

URL http://web.gfi.uib.no/\%7Engfls/frisp/Rep17/thoma05.pdf

Thoma, M., Grosfeld, K., Mayer, C., Dec. 2007. Modelling mixing and circulation in subglacial Lake Vostok, Antarctica. Ocean Dynamics 57 (6), 531-540, doi: 10.1007/s10236-007-0110-9.

Wingham, D. J., Siegert, M. J., Shepherd, A., Muir, A. S., 2006. Rapid discharge connects Antarctic subglacial lakes. Nature 440 (C6), 1033-1036, doi:10.1038nature04660.

Wüest, A., Carmack, E., 2000. A priori estimates of mixing and circulation in the hard-to-reach water body of Lake Vostok. Ocean Modelling 2 (1), $29-43$. 